\title{
Knowledge Management and Organizational Learning from the Employee Perspectives: A Study from Saudi Arabia Context
}

\author{
Wageeh $\mathrm{Nafei}^{1}$ \\ ${ }^{1}$ University of Sadat City, Menoufia, Egypt \\ Correspondence: Wageeh Nafei, University of Sadat City, Menoufia, Egypt. E-mail: dr.wageeh1965@yahoo.com
}

Received: December 1, 2013

Accepted: December 24, $2013 \quad$ Online Published: February 16, 2014

doi:10.5430/jms.v5n1p73

URL: http://dx.doi.org/10.5430/jms.v5n1p73

\begin{abstract}
This paper investigates the relationship between Knowledge Management (KM) and Organizational Learning (OL) from the employee perspective.

KM has emerged as one of the most important areas in management practices and established as a basic resource for firms and economies. KM is an area of research and practice that is still searching for a stable set of core concepts and practical applications.

$\mathrm{OL}$ is considered to be one of the most important issues in modern managerial literature. Also, OL is one of the most important organizational factors that can direct the behavior and attitudes of the employees in the organizations.

This study was conducted at Saudi banks in Al-Taif Governorate. It is practical, according to its purpose, and descriptive according to its data collection method.

The present study investigates the evaluative attitudes of the employees towards KM and OL. It will also illustrate the relationship between KM and OL. Two groups of employees were examined. Of the 350 questionnaires that were distributed, 285 usable questionnaires were returned, a response rate of $81 \%$.

The finding reveals that there are differences among the employees regarding their evaluative attitudes towards KM and OL. Also, this study reveals that there is a statistically significant relationship between KM and OL. Accordingly, the study provided a set of recommendations including the necessity to pay more attention to KM and OL. This will achieve its success currently and in the future, besides attaining a competitive advantage.
\end{abstract}

Keywords: knowledge management, organizational learning

\section{Introduction}

Knowledge Management (KM) has emerged as one of the most important areas in management practices. KM is regarded as collection, distribution and efficient use of knowledge resources. It is a process of knowledge creation, validation, presentation, distribution and evaluation (Tahir, et al., 2010).

KM is a process that transforms individual knowledge into organizational knowledge (Rašul, et al., 2012). KM is a process that helps organizations to find important information, select, organize and publish them; and it's a proficiency that will be necessary for actions like solving problems, dynamic learning, decision making (Nazari and Emami, 2012).

KM does not belong to one area; people from different disciplines are working on it. KM are still at emerging state and the process is ongoing, till we get a complete formal approach which shall be universally accepted (Anand \& Singh, 2011).

Organizational Learning (OL) is considered to be one of the most important issues in modern managerial literature. It has emerged as one of the most promising concepts in strategic management. The researcher in the field of OL stated that the ability to learn faster than your competitors may be the only sustainable competitive advantage (De Geus, 1988).

KM and OL are terms commonly used in today's business environment and usually associated with large budget projects pursued by firms convinced that the only competitive advantage the company of the future will have is its ability to learn faster than its competitors (DeGeus, 1988). 
$\mathrm{KM}$ and OL are concerned with developing, connecting, and empowering knowledge workers at all levels of the organization and with ensuring the enterprise can access, learn from, and leverage what it knows to create business value (Ives \& Combs, 2012).

The correlation between KM and OL was significant. Thus, the strength of the correlations suggests that OL has a significant role in KM (Farsan, et al., 2013).

The relationship between KM and OL is understandable; learning in itself creates new knowledge (Mishra \& Bhaskar, 2011; Sanz-Valle et al., 2011) and adds to existing knowledge (Pemberton \& Stonehouse, 2000). How knowledge is stored, translated, distributed and managed is viewed as a key ingredient for an organization's sustainability and success (Greiner et al., 2007; Jasimuddin, 2008).

Successful learning organizations create an organizational environment that combines KM with OL (Pemberton \& Stonehouse, 2000).

KM and OL are interwoven (Prugsamatz, 2010; Pun \& Nathai-Balkissoon, 2011), though organizations need convergent systems to capture KM and OL; all of which need energizing by appropriate leadership, vision, culture, structure and infrastructure (Carnall, 2007).

Many organizations have made significant efforts and considerable investment to KM (Crossan \& Bapuji, 2003). Therefore, there is little rigorous research in the literature to guide organizations on KM. The subject of KM is a modern subject of interest to a large number of researchers in the non-Arab environments (Marques \& Simon, 2006), but it is still in its infancy. Therefore, the current study is trying to shed light on KM and OL.

The organization, which has a unit specializing in the development of $\mathrm{KM}$, would be able to use its resources efficiently and effectively as that contributes to improving the quality of the product or service (Anantatmula, 2007; Choi et al., 2008; Zack, et al., 2009).

Despite the progress in the theoretical aspect of $\mathrm{KM}$, there is still a need for further study and investigation and analysis to enrich the theoretical and applied research (Marques \& Simon, 2006).

In the Arab environment, this issue is still in its infancy, and there are not enough theoretical writings on the subject. It has not received its share of attention in application. This reveals the importance of the present study theoretically and practically for determining the dimensions of KM and OL at Saudi banks. This study aims at identifying the extent of similarities or differences among the employees in regard to KM and OL. Also, it will recognize the relationship between KM and OL at Saudi banks in Al-Taif Governorate, KSA.

\section{Theoretical Perspectives}

\subsection{Key Terms Relevant To KM}

The important terms identified on the basis of the literature survey conducted are data, information, knowledge and wisdom. Data is un-processed facts and raw number collected from the business operation and application. Information is processed data and added value to determine purpose. Knowledge is an interpretation of information to improve the understanding of purpose and can be used for solving problem and wisdom includes the new activity to achieve purpose (Alryalat \& Alhawari, 2008).

Data is un-processed collection of details, with no purpose, value and meaning. "Information" is manipulated structured data, with little value and could be classified, structured and organized for use. "Knowledge" understanding and thoughtful information can be used to solve problems. Finally, "Wisdom" is a broadened knowledge through value and cleverness joined with more actions and activities (Karadsheh, et al., 2009).

In light of the above-mentioned definition, the researcher finds that knowledge in its wider sense constitutes the real wealth for each of the individuals or organizations, and it is a vital tool that helps organizations achieve their goals efficiently and effectively.

\subsection{Definition of Knowledge}

Knowledge is the result of merging information with practice, perspective and expression, resulting in insinuation and presents approaches and plans on which decision is based (Kahn \& Adams, 2000). Knowledge is information used for a resolving precise dilemma, which presents the realistic stage (Stollberg, et al., 2004).

Knowledge is an interpretation of information to improve the understanding of purpose and can be used for solving problem and wisdom includes the new activity to achieve purpose (Alryalat \& Alhawari, 2008).

To understand the word "knowledge", it seems to mean three things. They are as follows (Nickols, 2010): 
- First, it refers to a state of knowing, by which to be acquainted, to be aware of, to recognize facts, methods, principles, techniques. This corresponds to "know about."

- Second, the word "knowledge" refers to "the capacity for action," an understanding or grasp of facts, methods, principles and techniques sufficient to apply them in the course of making things happen. This corresponds to "know how."

- Third, the term "knowledge" refers to codified, captured and accumulated facts, methods, principles, techniques.

In light of the above, the researcher finds that knowledge in its wider sense constitutes the real wealth for each of the individuals or organizations, and it is a vital tool that helps organizations achieve their goals efficiently and effectively. It is also one of the tools that contribute to the improvement of organizational performance.

\subsection{Knowledge Accessibility}

\subsubsection{Tacit Knowledge}

Tacit Knowledge (TK) includes both technical and cognitive. Technical TK is demonstrated when people master a specific body of knowledge or use skills like those gradually developed by master craftsmen. Cognitive TK incorporates implicit mental models and perceptions that are so ingrained they are taken for granted (Sternberg, 1997). TK requires little or no time or thought and helps determine how organizations make decisions and influence the collective behavior of their members (Leibowitz \& Beckman, 1998). TK is personalized when specific expertise is used to provide creative, analytically rigorous advice on high-level strategic problems. This personalized TK fits the company culture, customer needs and standard reporting methods (Hansen et al., 1999).

TK is knowledge which cannot be expressed in verbal, symbolic, and written form. It is knowledge that exists in the human mind and the behavior of each individual separately, it is personal, and difficult to codify or document (Clark \& Rollo, 2001). TK is internal knowledge in the minds of individuals (Politis, 2003). It refers to personal knowledge deep-rooted in the experiences and personal experiences of individuals (Small \& Sage, 2005).

\subsubsection{Implicit Knowledge}

Implicit Knowledge (IK) is knowledge that can be expressed. Its existence is implied by or inferred from observable behavior or performance. This is the kind of knowledge that can often be taken out of a competent performer by a task analyst. In analyzing the task in which underwriters at any company processed applications, for instance, it quickly became clear that the range of outcomes for the underwriters' work took three basic forms: (1) they could approve the application, (2) they could deny it and (3) they could counter offer. Yet, not one of the underwriters articulated these as boundaries on their work at the outset of the analysis. Once these outcomes were identified, it was a comparatively simple matter to identify the criteria used to determine the response to a given application. In so doing, IK became EK (Anand \& Singh, 2011).

\subsubsection{Explicit Knowledge}

Explicit knowledge (EK) is highly codified and is transmittable in formal, systematic language. It can be expressed through various means, such as writing, drawing, or talking or any other means, and information technology allows the possibility to convert and transfer it (Nonaka \& Takeuchi, 1995). EK is carefully codified, stored in a hierarchy of databases and is accessed with high quality, reliable, fast information retrieval systems. Its assets can be reused to solve many similar types of problems or connect people with valuable, reusable knowledge (Hansen et al., 1999).

EK is technical or academic data or information that is described in formal language, like manuals, mathematical expressions, copyright and patents (Smith, 2001). EK refers to knowledge which exists in symbolic or written form. EK is embedded in standardized procedures (Martin \& Salomon, 2003).

EK is knowledge that can be shared with others, and relates to explicit data and information which can be obtained and stored in files and records of the organization. It is the official, regular, and communicable knowledge that may be learned. It takes different forms such as patents and copyrights, as in the form of products, the organization and working procedures, plans and standards (Davis, et al., 2005).

By using EK and TK, KM helps an organization deliver the right information to the right place and the right person at the right time. KM needs TK and EK, as both give added value to the organization, and help create an atmosphere of discussion between individuals, groups and communication with experts (Plessis, 2007).

\subsection{Knowledge Management}

$\mathrm{KM}$ is the systematic, explicit and deliberate building, renewal and application of knowledge to maximize an enterprise's knowledge-related effectiveness and returns on its knowledge assets and to renew them constantly (Wiig, 
2003). $\mathrm{KM}$ is the methodical means of administrating this valuable resource, by promoting an incorporated approach to identifying, capturing, structuring, organizing, retrieving, sharing, and evaluating an enterprise's knowledge assets (Kim et al., 2004).

$\mathrm{KM}$ is the knowledge-based management, connecting people to people and people to information to create competitive advantage (Nonaka, 2007). KM is a procedure, practice to accomplish process about knowledge, process for knowledge, and process from knowledge which leads to improve the internal and external operation (Alryalat \& Alhawari, 2008).

$\mathrm{KM}$ is a structured process with activities to capture, discover, create, filter, evaluate, store, share and apply knowledge from individuals to advance business processes and meet organization's objectives and goals (Karadsheh, et al., 2009). KM is a systematic and integrative process of coordinating organization wide activities of acquiring, creating, storing, sharing, diffusing and deploying knowledge by individuals and groups, in pursuit of organizational goals (Tahir, et al., 2010).

From the above-mentioned definitions, the researcher finds that KM is a set of interrelated activities, integrated and related knowledge in terms of creation, acquisition, organization, distribution and use by all employees of the organization.

\subsection{Knowledge Management Processes}

Knowledge Management Process (KMP) is the heart of KM. KMP is essential in modern and successful organizations which look at knowledge as a major factor in competitiveness. KM has been seen as a fast response to weakness and threats that affect the way of organization business.

Wiig, 2003 presents a model for the processes of KM, which include five main stages. This can be illustrated as follows:

1. Knowledge Creation indicates the organization's ability to identify information needs in a scientific manner.

2. Knowledge Acquisition is the organization's ability to acquire knowledge, store and keep it in order to use it.

3. Knowledge Organization is the organization's ability to classify knowledge and convert it to useful written materials (knowledge base), using modern technological methods.

4. Knowledge Distribution is the organization's ability to disseminate knowledge to the level of administrative organization, and every individual within each level of an administrative unit, whether by e-mail, meetings, training courses or other.

5. Use of Knowledge is the organization's ability to benefit from knowledge, and its circulation among all employees to increase functional skills, and creative abilities, which lead to improved quality of service provided by the organization to its customers.

\subsection{Organizational Learning $(O L)$}

OL has been regarded as one of the strategic means of archiving long-term organizational success. OL has become an increasingly important area recently (Liao \& Wu, 2009).

$\mathrm{OL}$ is a continuous testing of experience and its transformation into knowledge available to the whole organization and relevant to their mission (Senge, 1990). OL emerges when organizations acquire information of any kind by any means (Argyris \& Schön, 1996).

OL has many models and frameworks that explain how learning occurs at the individual, group and organizational level. OL models are: Single Loop Learning (SLL) and Double Loop Learning (DLL) (Argyris \& Schon, 1978).

Argyris (1992) develops the idea of learning by distinguishing between SLL and DLL. The objective of SLL is to bring organizational activity back on track. This is no doubt important, but does not foster organizational innovation. DLL is the ability of the organization's members to think critically and creatively about the underlying frameworks. First order strategies concern 'SLL', aimed at correcting and modifying practices to fit in with an established policy. Second order strategies are those of 'DLL', which-in parallel with second generation KM strategies aim to increase the organization's capacity to think creatively and act innovatively (Hovland, 2003).

The concept of OL was achieved by Senge (1990) as he presented the ideas of SLL and DLL or Adaptive Organizational Learning (AOL) and Generative Organizational Learning (GOL) (Stonehouse \& Pemberton, 1999). SLL is similar to AOL as proposed by Senge (1990). It focuses on evolutionary changes to counteract changes at the environment of the organization besides what it needs for survival. This type of learning does not achieve the 
competitive advantage of the organization, but it is necessary for its survival (Pemberton \& Stonehouse, 2000).

DLL is similar to GOL as proposed by Senge (1990). It focuses on creating new capabilities or discovering new opportunities as the present system is useless and must be changed (Altman \& Illes, 1998). The vital outcome of the DLL or GOL is the realization of high-specialization learning that may be generalized in all organizations of all conditions (Pemberton \& Stonehouse, 2000).

AOL is related to little change at the primary stage of learning while the GOL tries to improve the organization's ability to discover capabilities. Knowledge is transferred to modify conduct and to create new experiences. This means that GOL is an advance of AOL and complements it (Thomas \& Allen, 2006). AOL is related to rationality, defensive relationships, low freedom of choice, and discouragement of inquiry (Argyris et al., 1985). It can be described as coping and dealing with the current environment in new and better ways (Senge, 1992).

AOL refers to the capacity to be able to cope with changes in the environment, whether internal or external in origin. Without this capacity, living beings cannot mature, grow, or survive (Voci \& Young, 2001). AOL focuses on evolutionary change in agreement with what occurs in the organization's environment. This helps it survive and saves costs and time (Sun \& Scott, 2003).

AOL involves any improvement of the explicate order through a process of self-organization. It is a self-organizational process that might happen when individuals and groups within organizations exercise logic or deductive reasoning, concentrate, discuss, and focus on improving any mental model, knowledge, process (Chiva et al., 2010).

GOL is a process that involves searching for order, which is a holistic understanding of anything or anyone we interact with. When enacted or interpreted, this implicate order becomes a new explicate order, or the manifested world, which is represented through mental models, paradigms. It is a self-transcendence process that might take place when individuals and groups within organizations mainly use intuition, attention; dialogue and aim to question any explicate order or knowledge (Chiva et al., 2010).

GOL focuses on creating new capabilities and renouncing the old ways of work deliberately. This is necessary for the organization, which operates amid extreme changes. This type of learning is very costly (Wijnhoven, 2001). GOL is becoming essential in our organizations. There is still a need to improve our understanding of how GOL takes place in organizations, where it can be located in the OL process, and how can we enhance it. GOL is associated with intuition and attention, whereas AOL is linked to logical deductive reasoning and concentration (Chiva et al., 2010).

\section{Research Questions and Hypotheses}

The objective of this study is to analyze KM and its relation with OL at Saudi banks in Al-Taif Governorate, KSA. The research questions for this study are as follows:

Q1: Are there fundamental variations among the employees at Saudi banks in Al-Taif Governorate towards KM?.

Q2: Are there fundamental variations among the employees at Saudi banks in Al-Taif Governorate towards OL?.

Q3: What is the relationship between KM and OL at Saudi banks in Al-Taif Governorate, KSA?.

Drawing on these research questions, the research hypotheses of this study are as follows:

H1: There is no significant discrimination among the employees at Saudi banks in Al-Taif Governorate towards KM there.

H2: There is no significant discrimination among the employees at Saudi banks in Al-Taif Governorate towards OL there.

H3: There is no statistically significant relationship between KM and OL at Saudi banks in Al-Taif Governorate, KSA.

\section{Methodology and Research Design}

\subsection{Participants and Procedures}

This study investigates the attitudes of employees toward KM and OL. It was conducted at Saudi banks in Al-Taif Governorate, KSA. This is why the population under study involves all categories of employees.

Three hundred and fifty employees were randomly selected from the employees at Saudi banks. To ensure anonymity, they were asked not to put any form of identification on the questionnaire. The study questionnaire containing measures of KM and OL was distributed to employees using the drop-off method. 
A survey-based descriptive research design is used. The study was carried out at Saudi banks in Al-Taif Governorate, KSA. The questionnaire included three questions, relating to recognizing KM, OL, and demographic variables of employees at Saudi banks in Al-Taif Governorate, KSA. Few employees completed 25 questionnaires but some changes took place. The questionnaires were completed anonymously during group administration. Data collection took approximately two months. Overall, 285 respondents completed the questionnaire, for a response rate of $81 \%$.

Concerning the job title, managers amounted to about $8.8 \%$, controllers amounted to about $18.2 \%$, chief tellers $26.3 \%$, tellers $17.6 \%$, and customer services $29.1 \%$. In regard to marital status, the percentage of the married staff amounted to $72.3 \%$ and single staff $27.7 \%$. As for age, number of participants less than 30 was $41.8 \%$, from 30 to 45 was $50.2 \%$ and more than 45 was about $8 . \%$. Concerning the educational level, holders of the secondary school certificate amounted to $44.6 \%$, and university education $55.4 \%$. Regarding period of experience, the number of participants less than five years was about $18.2 \%$, from 5 to 10 years was $73 \%$ and more than 10 years of experience was $8.8 \%$.

\subsection{Research Variables and Methods of Measuring}

This research studied the relationship between KM and OL at Saudi banks in Al-Taif Governorate, KSA. In referencing exiting literature, the study established a basic research model. KM is independent variable; OL is the dependent variable. The study of data collected through questionnaires with three: KM, OL, and basic respondent demographic data. The survey uses the fifth - point Likert scale. The 25-item scale KM is based on Jakob, 2003; and Wiig, 2003. The 14- item scale OL is based on Senge et al., 1994; Voci \& Young, 2001; Smith \& Taylor, 2000; Appeldan \& Goramsson 1997; and Osterberg, 2004.

\subsection{Method of Data Analysis and Testing Hypotheses}

The researcher has employed the following methods: (1) the Alpha Correlation Coefficient (ACC), (2) the Multiple Discriminant Analysis (MDA), (3) Multiple Regression Analysis (MRA), and (4) the statistical testing of hypotheses which includes Wilk's Lambda and chi-square, F- test and T-test. All these tests are found in SPSS.

\section{Hypotheses Testing}

\subsection{Evaluating Reliability}

Data analysis was conducted in there major phases. Cronbach's alpha was used to assess the reliability of the scales. Item analysis indicated that dropping any items from the scales would not significantly raise the alphas.

Table 1. Reliability of KM and OL

\begin{tabular}{|c|c|c|c|}
\hline Variables & The Dimension & $\begin{array}{l}\text { Number of } \\
\text { Statement }\end{array}$ & $\mathrm{ACC}$ \\
\hline \multirow{6}{*}{$\mathbf{K M}$} & Knowledge Creation & 5 & 0.860 \\
\hline & Knowledge Acquisition & 5 & 0.753 \\
\hline & Knowledge Organization & 5 & 0.780 \\
\hline & Knowledge Distribution & 5 & 0.780 \\
\hline & Use of Knowledge & 5 & 0.677 \\
\hline & Total Measurement & 25 & 0.844 \\
\hline \multirow{3}{*}{ OL } & Adaptive Organizational Learning & 7 & 0.932 \\
\hline & Generative Organizational Learning & 7 & 0.926 \\
\hline & Total Measurement & 14 & 0.967 \\
\hline
\end{tabular}

According Table 3, the overall reliability of KM is 0.84 . The overall reliability of OL is 0.96 . All the measures of these scales were sufficiently reliable.

\subsection{Knowledge Management}

The statistical results for the evaluative attitudes of employees towards KM are studied. The first hypothesis to be tested is:

H1: There is no significant discrimination among the employees at Saudi banks in Al-Taif Governorate towards KM. 
Table 2. Discriminant functions and matrix on the basis of KM

\begin{tabular}{cccccccc}
\hline \multicolumn{7}{c}{ A- Discriminant Functions (DF) } \\
\hline \multirow{2}{*}{ Function } & Eigen & The \% of & MCC & Wilks & Ch-Squ & Degree & Level of \\
& Values & Differences & & Lambada & are & of Sign & Sign \\
1 & 0.208 & 66.4 & 0.415 & 0.749 & 80.983 & 10 & 0.000 \\
2 & 0.105 & 33.6 & 0.309 & 0.905 & 28.030 & 4 & 0.000 \\
\hline \multicolumn{7}{c}{ The Percentage of the exact division }
\end{tabular}

According to MDA, the most important findings include the following:

1. There is a relationship between Saudi banks of the employees groups and their evaluative attitudes towards KM (MCC represents 0.41 in the DF).

2. There is a high degree of difference among employees towards KM (the percentage of differentiation was $66 \%$ of DF).

3. The accurate classification of employees attitudes towards $\mathrm{KM}$ is $67 \%$. The remaining portions, $33 \%$, are similar.

4. There are five variables relating to KM. They have an ability to discriminate among employees (see Table 3). The most important of them are "the bank gains knowledge from similar banks"; (DC represent 0.60, "the bank identifies information needs to be able to provide them" (DC represent 0.59).

5. According to the mean of the three groups of employees (see Table 3). As for employees at the big Saudi banks, they tend to agree, for example, that "the bank identifies information needs to be able to provide them" (with a mean of 4.37). As for employees at the middle Saudi banks, they tend to agree, for example, that "the bank identifies information needs to be able to provide them" (with a mean of 3.97). As for employees at the small Saudi banks, they tend to agree, for example, that "the bank identifies information needs to be able to provide them" (with a mean of 4.87).

Table 3. Discrimination coefficients among the employees on the basis of KM

\begin{tabular}{|c|c|c|c|c|c|}
\hline The Variables & $\begin{array}{c}\text { Group } \\
1\end{array}$ & $\begin{array}{l}\text { Mean } \\
\text { Group } \\
2\end{array}$ & $\begin{array}{c}\text { Group } \\
\mathbf{3}\end{array}$ & F-Test & $\begin{array}{l}\text { Level } \\
\text { of Sig } \\
\text { DC }\end{array}$ \\
\hline $\begin{array}{l}\text { 1. The bank gains knowledge from similar } \\
\text { banks. }\end{array}$ & 4.07 & 3.69 & 4.30 & $8.651^{* *}$ & 0.602 \\
\hline $\begin{array}{l}\text { 2. The bank identifies information needs to be } \\
\text { able to provide them. }\end{array}$ & 4.37 & 3.97 & 4.87 & $9.193^{* *}$ & 0.597 \\
\hline $\begin{array}{l}\text { 3. The bank has a database for the classification } \\
\text { of knowledge. }\end{array}$ & 3.64 & 3.79 & 4.53 & $9.338^{* *}$ & 0.548 \\
\hline $\begin{array}{l}\text { 4. The use of knowledge helps employees to } \\
\text { raise the level of service provided to the } \\
\text { customers }\end{array}$ & 3.24 & 3.21 & 4.17 & $9.239^{* *}$ & 0.541 \\
\hline $\begin{array}{l}\text { 5. The use of knowledge raises staff creativity } \\
\text { and development }\end{array}$ & 3.71 & 3.37 & 3.30 & $9.160^{* *}$ & 0.323 \\
\hline
\end{tabular}

Accordingly, the null hypothesis is rejected because the value of Wilks Lambda amounts to 0.75. Moreover, the value of chi-square calculated (80.98) in the free degree of (10) exceeds its table counterpart (23.21). Furthermore, it was decided to reject the same null hypothesis of five variables of KM (25 variables) at the statistical significance level of 0.01 .

\subsection{Organizational Learning}

The statistical results for the evaluative attitudes of employees towards OL are judged. The second hypothesis to be tested is:

H2: There is no significant discrimination among the employees at Saudi banks in Al-Taif Governorate regarding $\boldsymbol{O L}$.

The MDA was applied on three groups of employees and their evaluative attitudes towards OL as displayed in Tables 
4 and 5.

Table 4. Discriminant functions and matrix on the basis of OL

\begin{tabular}{cccccccc}
\hline \multicolumn{7}{c}{ A- Discriminant Functions (DF) } \\
\hline \multirow{2}{*}{ Function } & Eigen & The \% of & MCC & Wilks & Ch-Squ & Degree & Level of \\
& Values & Differences & & Lambada & are & of Sign & Sign \\
1 & 0.041 & 100.0 & 0.200 & 0.960 & 11.462 & 2 & 0.000 \\
\hline \multicolumn{7}{c}{ The Percentage of the exact division } \\
\hline
\end{tabular}

According to MDA, the most important findings include the following:

1. There is relationship between Saudi banks of the employees groups and their evaluative attitudes towards OL(MCC represents 0.20 in the DF).

2. There is a high degree of difference among employees towards OL (the percentage of differentiation was $100 \%$ of DF).

3. The accurate classification of employees attitudes towards OL, is $65 \%$. The rest, $35 \%$, are similar.

4. There is one variable relating to OL. It has an ability to discriminate among employees (see Table 6). This variable is "bank administration is trying to deal with anything that happens in the external environment" (discrimination coefficients represent 1.00).

5. According to the mean of the three groups of employees (see Table 6). As for employees at the big Saudi banks, they tend to agree that "bank administration is trying to deal with anything that happens in the external environment"(with a mean of 3.46). As for employees at the middle Saudi banks, they tend to agree that "bank administration is trying to deal with anything that happens in the external environment" (with a mean of 3.54). As for employees at the small Saudi banks, they tend to agree that "bank administration is trying to deal with anything that happens in the external environment" (with a mean of 3.97).

Table 5. Discrimination coefficients among the employees on the basis of OL

\begin{tabular}{lcccccc}
\hline The Variables & $\begin{array}{c}\text { Mean } \\
\text { Group } \\
\mathbf{1}\end{array}$ & $\begin{array}{c}\text { Group } \\
\mathbf{2}\end{array}$ & $\begin{array}{c}\text { Group } \\
\mathbf{3}\end{array}$ & F-Test $\begin{array}{c}\text { Level } \\
\text { of Sig }\end{array}$ \\
\hline $\begin{array}{l}\text { 1. Bank administration is trying to deal with } \\
\text { anything that happens in the external } \\
\text { environment. }\end{array}$ & 3.46 & 3.54 & 3.97 & $5.849^{* *}$ & 1.000 \\
\hline
\end{tabular}

Accordingly, the null hypothesis is rejected because the value of Wilks Lambda amount to 0.96. Besides the value of chi-square calculated (11.46) in the free degree of (2) exceeds its table counterpart (9.31). Furthermore, it was decided to reject the same null hypothesis of one variable of OL (14 variables) at the statistical significance level of 0.01 .

5.4 The Relationship between KM and $O L$

The statistical results for the relationship between $\mathrm{KM}$ and OL are studied. The third hypothesis to be tested is:

H3: There is no statistically significant relationship between KM and OL at Saudi banks in Al-Taif Governorate.

Table 6. Correlation coefficients between KM and OL

\begin{tabular}{lccc}
\hline \multirow{2}{*}{ The Dimension of KM } & \multicolumn{2}{c}{ The Dimension of OL } & Total \\
& AOL & GOL & OL \\
\hline Knowledge Creation & 0.049 & 0.056 & 0.053 \\
Knowledge Acquisition & $0.703^{* *}$ & $0.707^{* *}$ & $0.707^{* *}$ \\
Knowledge Organization & $0.700^{* *}$ & $0.704^{* *}$ & $0.704^{* *}$ \\
Knowledge Distribution & 0.014 & 0.012 & 0.013 \\
Use of Knowledge & $0.551^{* *}$ & $0.564^{* *}$ & $0.559^{* *}$ \\
\hline \multicolumn{1}{c}{ Total Measurement } & $\mathbf{0 . 5 7 0}^{* *}$ & $\mathbf{0 . 5 7 4}^{* *}$ & $\mathbf{0 . 5 7 4}^{* *}$ \\
\hline
\end{tabular}

According to Table 6 , there is a statistically significant correlation between the aspects of KM and OL. The following section will discuss the relationship between the aspects of KM and OL. 
5.4.1 The Relationship between KM (Knowledge Creation) and OL

Table 7. The relationship between knowledge creation and OL

\begin{tabular}{|c|c|c|c|}
\hline The Variables of Knowledge Creation & Beta & $\mathrm{R}$ & $\mathrm{R}^{2}$ \\
\hline The bank identifies information needs to be able to provide them. & 0.100 & 0.011 & 1.21 \\
\hline $\begin{array}{l}\text { The bank employs scientific research in the provision of knowledge } \\
\text { related to its objectives. }\end{array}$ & 0.058 & 0.062 & 3.84 \\
\hline Views and experiences are recorded and saved in the database. & $0.195^{*}$ & 0.105 & 0.01 \\
\hline The bank's seeking to provide data to fill the knowledge gap. & 0.098 & 0.004 & 1.60 \\
\hline $\begin{array}{l}\text { The availability of bank data helps employees to solve problems that } \\
\text { face them. }\end{array}$ & 0.010 & 0.026 & 6.76 \\
\hline - Multiple Correlation Coefficients (MCC) & & 0.149 & \\
\hline - Determination of Coefficient (DF) & & 0.022 & \\
\hline - The Value of Calculated F & & 1.273 & \\
\hline - Degree of Freedom & & 5,279 & \\
\hline - The Value of Indexed F & & 3.02 & \\
\hline - Level of Significant & & 0.267 & \\
\hline
\end{tabular}

According to the results of MRA, there is a relationship between knowledge creation and OL in significance level of 0,000 . As a result of the value of $\mathrm{R}^{2}$, knowledge creation can explain $2 \%$ of the total differentiation in OL level.

For the results of a structural analysis of the MRA model, the direct effect of knowledge creation and OL is obtained. Because MCC is 0.15, then it is concluded that there is enough empirical evidence to reject the null hypothesis.

5.4.2 The Relationship between KM (Knowledge Acquisition) and OL

Table 8. The relationship between knowledge acquisition and OL

\begin{tabular}{lccc}
\hline \multicolumn{1}{c}{ The Variables of Knowledge Acquisition } & Beta & $\mathrm{R}$ & $\mathrm{R}^{2}$ \\
\hline The bank gains knowledge from similar banks. & $0.328 * *$ & 0.585 & 0.342 \\
The bank gains knowledge through consultants in scientific institutes. & $0.281^{* *}$ & 0.562 & 0.315 \\
The bank tries to acquire knowledge through bank around. & $0.199^{* *}$ & 0.600 & 0.360 \\
The bank helps employees acquire knowledge in different fields. & 0.035 & 0.495 & 0.245 \\
The employees acquire knowledge through libraries and the Internet. & $0.151^{* *}$ & 0.290 & 0.084 \\
- Multiple Correlation Coefficients (MCC) & & 0.728 & \\
- Determination of Coefficient (DF) & \multicolumn{2}{c}{0.530} \\
- The Value of Calculated F & \multicolumn{2}{c}{63.028} \\
- Degree of Freedom & \multicolumn{3}{c}{5,279} \\
The Value of Indexed F & 3.02 & \\
- Level of Significant & & 0.00 & \\
\hline$* * \mathrm{P}<.01$ & & &
\end{tabular}

Regarding to the results of MRA, there is a relationship between knowledge acquisition and OL in significance level of 0,000 . As a result of the value of $\mathrm{R}^{2}$, knowledge acquisition can explain $52 \%$ of the total differentiation in $\mathrm{OL}$ level.

The results of a structural analysis of the MRA model directly influence knowledge acquisition variable toward OL. Because MCC is 0.73, then there is enough empirical evidence to reject the null hypothesis.

5.4.3 The Relationship between KM (Knowledge Organization) and OL

Table 9. The relationship between knowledge organization and OL

\begin{tabular}{lccc}
\hline The Variables of Knowledge Organization & Beta & $\mathrm{R}$ & $\mathrm{R}^{2}$ \\
\hline The bank selects modern methods of organizing knowledge. & $0.314^{* *}$ & 0.583 & 0.334 \\
The bank classifies the data to take advantage of them. & $0.300^{* *}$ & 0.595 & 0.354 \\
The bank classifies primary data and converts them to information. & $0.175^{* *}$ & 0.601 & 0.361 \\
The bank has a database for the classification of knowledge. & 0.011 & 0.493 & 0.243 \\
The bank specifies all what is new for the organization and & $0.170^{* *}$ & 0.304 & 0.092 \\
classification of knowledge. & & 0.724 & \\
- Multiple Correlation Coefficients (MCC) & 0.524 \\
- Determination of Coefficient (DF) & 61.411 \\
- The Value of Calculated F & 5,279 \\
- Thegree of Freedom & 3.02 & \\
- Level of Significant & & 0.05 & \\
\hline$* * \mathrm{P}<.01$ & & & \\
\hline
\end{tabular}


Concerning the results of MRA, there is a relationship between knowledge organization and OL in significance level of 0,000 . As a result of the value of $\mathrm{R}^{2}$ definiteness coefficient, knowledge organization can explain $52 \%$ of the total differentiation in OL level.

According to the results of MRA, the there is a fundamental relationship between knowledge organization and OL. Because MCC is 0.72, then it is concluded that there is evidence to reject the null hypothesis.

5.4.4 The Relationship between KM (Knowledge Distribution) and OL

Table 10. The relationship between knowledge distribution and OL

\begin{tabular}{lccc}
\hline \multicolumn{1}{c}{ The Variables of Knowledge Distribution } & Beta & $\mathrm{R}$ & $\mathrm{R}^{2}$ \\
\hline The bank distributes knowledge through e-mail. & 0.072 & 0.041 & 1.681 \\
The bank wishes issue bulletins for the knowledge distribution. & 0.032 & 0.006 & 0.000 \\
There is a bank system that contributes to the distribution of & 0.006 & 0.003 & 0.000 \\
knowledge on the right time & 0.025 & 0.100 & 0.010 \\
The bank uses the meetings as a means to distribute knowledge. & 0.008 & 0.005 & 0.000 \\
The bank holds training courses on how to use knowledge. & & 0.055 & \\
- Multiple Correlation Coefficients (MCC) & & 0.003 & \\
- Determination of Coefficient (DF) & & 0.171 & \\
- The Value of Calculated F & & 5,279 & \\
- Degree of Freedom & & 3.02 & \\
- The Value of Indexed F & & 0.973 & \\
\hline
\end{tabular}

According to the results of MRA, there is a relationship (0.55) between knowledge distribution and OL in significance level of 0,000 . As a result of the value of $R^{2}$ definiteness coefficient, knowledge distribution can explain $3 \%$ of the total differentiation in OL level.

For the results of a structural analysis of the MRA model, the direct effect of knowledge distribution and OL is obtained. Because MCC is 0.55 , then it is concluded that there is enough empirical evidence to reject the null hypothesis.

5.4.5 The Relationship between KM (Use of Knowledge) and OL

Table 11. The relationship between the use of knowledge and OL

\begin{tabular}{lccc}
\hline \multicolumn{1}{c}{ The Variables of Use of Knowledge } & Beta & $\mathrm{R}$ & $\mathrm{R}^{2}$ \\
\hline Uses the knowledge among employees in the same administrative & $0.107^{*}$ & 0.317 & 0.100 \\
level bank. & & & \\
Knowledge is traded among workers in the different administrative & $0.268^{* *}$ & 0.325 & 0.105 \\
levels within the bank. & 0.079 & 0.315 & 0.009 \\
The use of knowledge increases the functional skill of employees. & $0.263^{* *}$ & 0.463 & 0.214 \\
The use of knowledge helps employees to raise the level of service & $0.338^{* *}$ & 0.427 & 0.182 \\
provided to the customers. & & 0.602 & \\
The use of knowledge helps staff creativity and development. & 0.362 & \\
- Multiple Correlation Coefficients (MCC) & 31.685 & \\
- Determination of Coefficient (DC) & 5,279 & \\
- The Value of Calculated F & & 3.02 & \\
- Degree of Freedom & & 0.000 & \\
- Le Value of Indexed F & & & \\
\hline$* \mathrm{P}<.05$ & & & \\
\hline
\end{tabular}

Regarding to the results of MRA, there is a relationship (0.60) between the use of knowledge and OL in significance level of 0,000 . As a result of the value of $\mathrm{R}^{2}$ definiteness coefficient, the use of knowledge can explain $31 \%$ of the total differentiation in OL level.

The results of a structural analysis of the MRA model directly influence the use of knowledge variable toward OL. Because MCC is 0.60, then there is enough empirical evidence to reject the null hypothesis.

\section{Discussion of the Findings}

The present study on analyzing the relationship between KM and OL at Saudi banks in Al-Taif Governorate reveals a 
set of results. The most important are summarized as follows:

1. The researcher was able to determine that differences exist among the employees at Saudi banks regarding their evaluative attitudes towards KM, most importantly "the bank gains knowledge from similar banks, "the bank identifies information needs to be able to provide them", "the bank has a database for the classification of knowledge", "the use of knowledge helps employees to raise the level of service provided to the customers", and "the use of knowledge helps staff creativity and development".

2. The researcher was able to determine that differences exist among the employees at Saudi banks regarding their evaluative attitudes towards OL, most importantly "the bank administration is trying to deal with anything that happens in the external environment".

3. There is a statistically significant relationship between the dimensions of KM (knowledge creation, knowledge acquisition, knowledge organization, knowledge distribution, and use of knowledge) and OL (AOL and GOL) at Saudi banks in Al-Taif Governorate.

\section{Recommendations}

\subsection{Recommendations Relating to KM}

1. All employees should deepen the concept of KM and its importance and access to best practices in KM and application through specialized training programs that aim to develop the capacity of employees and develop their skills and knowledge.

2. Designing and implementing a range of training programs for all employees for the development and improvement of KM in terms of knowledge creation, acquisition, organization, distribution and use. This can be done through the development of awareness among employees of the concept, importance, and dimensions of KM.

3. KM achieve a number of important benefits including the development and growth of Saudi banks and their employees, improving the communication process the ability to make decisions, achieve competitive advantage, improve financial performance, and increase the value of Saudi banks from a market perspective.

4. Developing the skills and capabilities of employees in the field of KM, through specialized training programs that focus on $\mathrm{KM}$ as one of the methods that can be used to improve OL, and to achieve competitive advantage.

5. Increasing the interest of employees to possess self-knowledge of their employees, through paying attention to selection of new employees who possess knowledge of medical excellence, and providing employees with current medical knowledge, as this reflects the positive impact on the performance of Saudi banks.

6. Increasing the interest of employees, both types of knowledge implicit and explicit, through the activation of knowledge generation processes, inventory and configuration of ideas, experience and skills available to the employees and saving knowledge bases in order to facilitate reference.

\subsection{Recommendations Relating to $O L$}

1- The vision and mission of the organization should be clear to each employee, which is transformed into organizational objectives. Employees should be given more authority to achieve mutually settled goals. In addition, the supervisor needs to foster innovative thinking to look at the existing working criteria in new ways to enhance individual and group productivity.

2- It is necessary to pay more attention to OL. Its officials should realize and spend lavishly on the important OL as a learning organization. This will achieve its success currently and in the future, besides attaining the competitive advantage.

3- Reviewing the methods for selecting administrative leaders of Saudi banks, and the need for attention by choosing individuals with excellent interpersonal skills, out of the importance of leadership in achieving the OL of both types (AOL and GOL).

4- It is necessary to have more studies on $\mathrm{OL}$ and its relation to organizational performance so as to update it to catch up with academic developments in fields of knowledge

5- Saudi banks should pay more attention to GOL. This may be accomplished through various means, which include (1) searching for experienced persons in modern management, (2) recognizing the desires and needs of employees, and (3) granting employees more authority for urging them to provide new development in their specialization. 


\section{Conclusion and Implications}

\subsection{Academic Implications}

Our findings reveal that there KM discuss different influence on OL. Some authors find these two focuses as a cause and effect simultaneously, and some authors take OL as a cause, KM is an effect; or vice versa. In these studies, researchers implicitly assume a perspective of $\mathrm{OL}->\mathrm{KM}$ effect in which the causal direction runs primarily from OL to KM. And a KM -> OL effect could also account for the associations between KM and OL (Su, et al., 2003, 2004). OL is viewed as a reaction to KM rather than an action that contributes to KM (Liao, et al., 2008; Senge, 1990; Liao \& Wu, 2009; Liao \& Wu, 2009; Nonaka \& Takeuchi, 1995; Su, et al., 2004; Ke \& Wei, 2006).

Therefore, this research adopt KM $\rightarrow>$ OL effect which view OL as a reaction to KM at Saudi banks in Al-Taif Governorate, KSA.

\subsection{Practical Implications}

The present study is one of the pioneer works on the subject in KSA organizational context in areas of KM. This paper investigates the relationship between KM and OL from the employee perspective at Saudi banks in Al-Taif Governorate, KSA. There are several contributions in this paper. First, a theoretical framework is provided for empirical study on KM. Second, the relationship between KM and OL is addressed.

The findings of the research help KM researchers as well as practitioners develop a better understanding of the role of successful implementation of KM. The current study may provide necessary guidelines to understand the issues of $\mathrm{KM}$ and OL. Also, the findings of this study provide an initial understanding of the way towards further research in this area.

The results showed the significant and meaningful correlations between KM and OL sub-scales. Thus, the strength of the correlations obtained in the present research suggests that the overall OL and its sub-scales have a significant role in KM. Based on these results, KM is a divergence from the literature on the OL (Swan et al., 1999). OL requires individual personal knowledge to transform into information that other members of the organization can use (Jensen, 2005).

KM refers to the process in which organizations assess the data and information that exist within them, and is a response to the concern that people must be able to translate their learning into usable knowledge (Kezar, 2005).

During the KM the knowledge goes through different changes, and there are knowledge losses, both desirable and undesirable, where undesirable losses should be minimized as much as possible (Aggestam, 2006).

Successful KM is believed to have the potential of enhancing an organization's competitive advantage, customer focus, employee relations and development, innovation, and lower costs (Zheng, et al., 2010).

OL process is a sequence of three phases: information acquisition, information interpretation, and behavioral and cognitive changes. Hospitals that have developed a strong learning culture are good at creating, acquiring and transferring knowledge, as well as at modifying behavior to reflect new knowledge and insight (Garvin, 1993).

Organizations stressing learning must first acquire information, interpret it to fully understand its meaning and transform it into knowledge. At the same time, they must not forget the most important part-to implement behavioral and cognitive changes to convert words into action (Tomislav, 2008). Furthermore, learning, through better knowledge and understanding, facilitates behavior changes that lead to improved performance (Senge, 1990).

KM implementation is the ability of organization to acquire, converse, and apply their knowledge. This research provides attention to the relationship between KM and OL. We hope it encourage researchers to clarify the important relationship among capability behavior patterns, and measures of organizational performance, leading to more comprehensive investigations.

The research has investigated how Saudi banks can use KM successfully and its success factors in KM. There are a few significant implications. First, the management implications are made to help the investigated bank, as well as other banks that practice the use of KM. Second, this inquiry into KM suggests that future research in this area should pay equal attention to knowledge processes and organizational memory infrastructures. Often organizations will build knowledge processes but will not invest in the infrastructure where the knowledge resides and which facilitates the knowledge processes, or vice versa. Thus, an identification of knowledge processes in the knowledge evolution cycle will enable researchers to offer prescriptions to managers that can improve organizations' overall learning capabilities. Better management of learning is an important concern of most organizations. 


\section{Limitations and Future Research}

In spite of the interesting implications, this study has several limitations as follows. First, this study tried to avoid response bias through careful questionnaire design, we were not totally free from such bias. Second, the results from this survey were limited to Saudi banks in Al-Taif Governorate, KSA. Therefore, the results of this study may have to be carefully interpreted.

The findings of this study provide an initial understanding and pave the way for further research in this area. The future research could replicate and extend this research to enrich and enhance these preliminary findings in our context by exploring it in different organizational settings. Further prospective studies on KM and its impact on some variables such as job performance, innovation organizational, strategic performance, and effectiveness of managers in different organizations can be applied to other communities such as private universities, school districts, as well as public and private hospitals. Furthermore, the future research may focus on other important areas of KM. The strength of relationship between formalization and knowledge creation is in counterintuitive direction and needs further exploration.

\section{References}

Aggestam, L. (2006). Wanted: A Framework for IT-supported KM. Proceedings of the 17th Information Resources Management Association (IRMA), PP.21-24.

Aggestam, L. (2006). Learning Organization or Knowledge Management-which came first, the chicken or the egg? Information Technology and Control, 35(3A), 295-302.

Alryalat H., \& Al-Hawari S. (2008). A Review of Theoretical Framework: How to Make Process about, for, from Knowledge Work, In Proceedings of 9th International Business Information Management Association Conference, Marrakech, Morocco, PP.37-50.

Altman, Y., \& Illes, P. (1998). Learning, Leadership, Teams: Corporate Learning and Organizational Change. Journal of Management Development, 17(1), 44-55. http://dx.doi.org/10.1108/02621719810368682

Anand, A., \& Singh, M. (2011). Understanding Knowledge Management: A Literature Review. International Journal of Engineering Science and Technology, 3(2), 926-939.

Anantatmula, V. (2007). Linking Knowledge Management Effectiveness Attributes To Organizational Performance. VINE, 37(2), 133-149. http://dx.doi.org/10.1108/03055720710759928

Argyris, C., \& Schon D. (1978). Organizational Learning: A Theory of Action Perspective. MA: Addison- Wesley.

Argyris, C. (1992). Overcoming Organizational Defenses: Facilitating Organizational Learning. Boston, Allyn and Bacon.

Argyris, C., Putman, R., \& McLain Smith, D. (1985). Action Science, Concepts, Methods, and Skills for Research and Intervention. San Francisco, Jossey Bass.

Argyris, C., \& Schön, D. (1996). Organizational Learning II: Theory, Method and Practice. Reading, MA: Addison-Wesley.

Carnall, C. (2007). The Learning Organisation. Managing Change in Organizations (Fifth ed.). Ch10, PP. 160-170. Financial Times Prentice Hall.

Chiva, R., Grandío, A., \& Alegre, J. (2010). Adaptive and Generative Learning: Implications from Complexity Theories. International Journal of Management Reviews, 12(2), 114-129. http://dx.doi.org/10.1111/j.1468-2370.2008.00255.x

Choi, B., Poon, S., \& Davis, J. (2008). Effects of Knowledge Management Strategy on Organizational Performance: A Complementarity Theory-Based Approach. Omega, 36(2), 235-251. http://dx.doi.org/10.1016/j.omega.2006.06.007

Clark, T., \& Rollo, C. (2001). Corporate Initiatives in Knowledge Management. Education Training, 4(5), 206-241. http://dx.doi.org/10.1108/00400910110399201

Crossan, M., \& Bapuji, H. (2003). Examining the Link between Knowledge Management, Organizational Learning and Performance, Paper Presented to the 5th International Conference, London, Ontario, Canada, PP1-13

Daniel W. (1999). Biostatistics: A Foundation for Analysis in the Health Sciences ( $7^{\text {th }}$ ed.). New York, John Wiley \& Sons. 
Davis, J., Subrahmanian, E., \&Westerberg, A. (2005). The Global and Local in Knowledge Management. Journal of Knowledge Management, 9(1), 101-12. http://dx.doi.org/10.1108/13673270510582992

De Geus, A. P. (1988). Planning as Learning. Harvard Business Review, 88(2), 70-74.

Farsan, M., Rizi, R., \& Shahram, A. (2013). Relationship Between Knowledge Management and Organizational Learning Among Physical Education Teachers. European Journal of Experimental Biology, 3(1), 526-530.

Garvin, D. (1993). A. Building a learning organization. Harvard Business Review, 71(4), 78-91.

Greiner, M., Bohmann, T., \& Krcmar, H. (2007). A Strategy for Knowledge Management. Journal of Knowledge Management. 11(6), 3-15. http://dx.doi.org/10.1108/13673270710832127

Hansen, M., Nohria, N., \& Tierney, T. (1999, March-April). What's Your Strategy for Managing Knowledge? Harvard Business Review, 106-116.

Hovland, I. (2003). Knowledge Management and Organizational Learning: An International Development Perspective, Working Paper 224, London, Overseas Development Institute, Retrieved from www. odi.org.UK/Publications

Ives, C., \& Combs, B. (2012). The Application of Knowledge Management and Organizational Learning to Innovation Performance. Universal Journal of Management and Social Sciences, 2(10), 26-42.

Jasimuddin, S.M. (2008). A Holistic View of Knowledge Management Strategy. Journal of Knowledge Management, 12(2), 57-66. http://dx.doi.org/10.1108/13673270810859514

Kahn, B., \& Adams, E. (2000). Sales Forecasting as a Knowledge Management Process. The Journal of Business Forecasting, 19-22.

Karadsheh, L., Mansour, E., Alhawari, S., Azar, G., \& El-Bathy, N. (2009). A Theoretical Framework for Knowledge Management: Towards Improving Knowledge Performance. Communications of the IBIMA, 7, 67-79.

Ke, W., \& Wei, K. (2006). Organizational Learning Process: Its Antecedents and Consequences in Enterprise System Implementation. Journal of Global Information Management, 14(1), 1-22. http://dx.doi.org/10.4018/jgim.2006010101

Kezar. A. (2005). What Campuses Need to Know About Organizational Learning and the Learning Organization. New Directions for Higher Education, (131), 7-22. http://dx.doi.org/10.1002/he.183

Liao, S., \& Wu, C. (2009). The Relationship among Knowledge Management, Organizational Learning, and Organizational Performance. International Journal of Business and Management, 4(4), 64-76.

Marques, D., \& Simon, F. (2006). The Effect of Knowledge Management Practices on Firm Performance. Journal of Knowledge Management, 10(3), 143-156. http://dx.doi.org/10.1108/13673270610670911

Martin, X., \& Salomon, R. (2003). Tacitness, Learning, and International Expansion: A Study of Foreign Direct Investment in a Knowledge-Intensive Industry. Organization Science, 14(3), 297-311. http://dx.doi.org/10.1287/orsc.14.3.297.15165

Mishra, B., \& Bhaskar, U. (2011). Knowledge Management Process in Two Learning Organisations. Journal of Knowledge Management, 15(2), 344-359. http://dx.doi.org/10.1108/13673271111119736

Nickols, F. (2010). The Knowledge in Knowledge Management. Retrieved. Retrieved from http://www.jeslen.com/knowledge_in_Knowledge Management

Nonaka, I. (2007). Strategy as Distributed Phronesis: Knowledge Creation for the Common Good. Proceedings of the International Productivity Conference, Bangkok, Thailand, Knowledge Management: From Brain to Business Proceedings.

Nonaka, I., \& Takeuchi, H. (1995). The Knowledge-Creating Company. Oxford University Press, New York.

Pemberton, J., \& Stonehouse, G. (2000). Organizational Learning and Knowledge Assets: An Essential Partnership. The Learning Organization, 7(4), 184-193. http://dx.doi.org/10.1108/09696470010342351

Plessis, M. (2007). Knowledge Management: What Makes Complex Implementation Successful? Journal of Knowledge Management, 11(2), 91-101. http://dx.doi.org/10.1108/13673270710738942

Politis, J. (2003). The Connection Between Trust and Knowledge Management: What Are Its Implication for Team Performance. Journal of Knowledge Management, 7(5), 55-66. http://dx.doi.org/10.1108/13673270310505386

Prugsamatz, R. (2010). Factors that Influence Organization Learning Sustainability in Non-profit Organizations. The Learning Organization, 17(3), 243-267. http://dx.doi.org/10.1108/09696471011034937 
Pun, K., \& Nathai-Balkissoon, M. (2011). Integrating Knowledge Management into Organizational Learning Models: A Review of Concepts and Models. The Learning Organization, 18(3), 203-223. http://dx.doi.org/10.1108/09696471111123261

Randerre, E. (2006). Knowledge Management: Securing the Future. Journal of Knowledge Management, 10(4), 144-156.

Sanz-Valle, J. Naranjo-Valencia, J. Jimenez-Jimenez, \& PerezCabellero, L. (2011). Linking Organizational Learning with Technical Innovation and Organizational Culture. Journal of Knowledge Management, 15(6), 997-1015. http://dx.doi.org/10.1108/13673271111179334

Senge, P. M. (1990). The Fifth Discipline: The Art and Practice of Learning Organization. New York: Currency Doubleday.

Senge, P. (1992, March-April). Mental models. Planning Review, 44, 4-10. http://dx.doi.org/10.1108/eb054349

Small, C., \& Sage, A. (2005). Knowledge Management and Knowledge Sharing: A Review. Information Knowledge Systems Management, 5(33), 153-169.

Smith, E. (2001). The Role of Tacit and Explicit Knowledge in the Workplace. Journal of Knowledge Management, 5(4), 311-321. http://dx.doi.org/10.1108/13673270110411733

Sternberg, R. (1997). Successful Intelligence. Penguin Putnam, New York.

Stollberg M., Zhdanova, A., \& Fensel, D. (2004). H-TechSight A Next Generation Knowledge Management Platform. Journal of Information and Knowledge Management, 3(1), 46-66. http://dx.doi.org/10.1142/S0219649204000651

Stonehouse, G., \& Pemberton, J. (1999). Learning and Knowledge Management in the Intelligent Organization. Participation and Empowerment: An International Journal, 7(5), 131-144. http://dx.doi.org/10.1108/14634449910287846

Su, K., Hsieh, H., \& Liu, K. (2003). Application of the Learning Organization Paradigm in Engineering Education: An Empirical Research of Universities in Taiwan. World Transactions on Engineering and Technology Education, 2(2), 285-290.

Swan, H. Scarborough, \& J. Preston. (1999). Knowledge Management: The Next Fad to Forget People, Proceedings of the $7^{\text {th }}$ European Conference on Information Systems, Copenhagen Business School Copenhagen, Denmark, PP. 668-678.

Su, K., Huang, L., \& Hsieh, H. (2004). The Development of a Knowledge Flow Paradigm in Engineering Education: Empirical Research in Taiwanese Universities. World Transactions on Engineering and Technology Education, $3(1), 125-128$.

Sun, P., \& Scott, J. (2003). Exploring the Divide-Organizational Learning and Learning Organization. The Learning Organization, 10(4), 202-215. http://dx.doi.org/10.1108/09696470310476972

Tahir, S., Basit, T., Haque, M., Mushtaq, A., \& Anwar, C. (2010). Knowledge Management Practices: Role of Organizational Cultural, Proceedings of ASBBS, ASBBS Annual Conference, Las Vegas, 17(1), PP.1027-1036.

Thomas, K., \& Allen, S. (2006). The Learning Organization: A Meta-Analysis of Themes in Literature. The Learning Organization, 13(2), 123-139. http://dx.doi.org/10.1108/09696470610645467

Tomislav H., Miha Š.J., \& Vlado D. (2008). Relationship between Organizational Learning and Organizational Performance: The Case of Croatia. Transformation in Business \& Economics, 4(2), 1-17.

Voci, E., \& Young, K. (2001). Blended Learning Working in A Leadership Development Program. Industrial and Commercial Training, 33(5), 157-160. http://dx.doi.org/10.1108/00197850110398927

Wiig, K. (2003). Knowledge Management Foundation, Thinking About Thinking-How People and Organizations Represent Create and Use Knowledge. Arlington, Schema Press, Arlington, Texas.

Wijnhoven, F. (2001). Acquiring Organizational Learning Norms: A Contingency Approach for Understanding Deutero Learning. Management Learning, 32(2), 181-200. http://dx.doi.org/10.1177/1350507601322002

Zack, M., McKeen J., \& Singh, S. (2009). Knowledge Management and Organizational Performance: An Exploratory Analysis. Journal of Knowledge Management, 13(6), 392-409. http://dx.doi.org/10.1108/13673270910997088

Zheng, W., Yang, B., \& Mclean, G. (2010). Linking Organizational Culture, Strategy and Organizational Effectiveness; Mediating Role of Knowledge Management. Journal of Business Research, 63, 763-771. http://dx.doi.org/10.1016/j.jbusres.2009.06.005 